\title{
Children's Access to Primary and Secondary Education in Slum Settlements of Zimbabwe: Insights from Hopley Farm
}

\author{
Chipo Chitereka ${ }^{1}$, Dr. Edmos Mtetwa ${ }^{2}$, Prof Innocent Chirisa ${ }^{3}$ \\ University of Zimbabwe
}

\begin{abstract}
This paper discusses factors influencing access to education for children living in slum settlements of Zimbabwe. It also proffers suggestions that can be adopted to improve access to education for slum dwellers. Education is a basic human right enshrined in many international documents and treaties. As such, governments should guarantee that education in their countries is available, accessible, acceptable and adaptable and see to it that all children can acquire the education they are entitled. Equal access to education is a fundamental mechanism through which individuals can integrate into the mainstream society and a means to realising other rights. However, for slum settlements inhabitants, the realisation of this basic human right is characterised by a plethora of challenges since slums are impoverished disadvantaged communities with inadequate or lack of educational services.
\end{abstract}

Keywords: access to education; challenges; children; slum settlement inhabitants 